\section{Absence of flexor carpi radialis: A rare anatomical variation with clinical significance}

Sir,

The importance of flexor carpi radialis (FCR) as a donor muscle in tendon transfers, ${ }^{[1,2]}$ as a tendon graft ${ }^{[3,4]}$ and as an anatomical landmark has been well established. The anatomical variations of FCR are very rare but can have great significance in such cases. ${ }^{[5,6]}$ We report a rare case of congenital absence of FCR muscle found during an elective surgery of bone grafting for scaphoid non-union.

We present the case of a 20 -year-old male patient who presented to us with established non-union of the left scaphoid. Open reduction and internal fixation with bone grafting of the scaphoid through a volar approach was discussed and planned. During skin marking for the volar approach, the FCR tendon could not be palpated. Therefore, we made the skin incision across the wrist crease with the scaphoid tubercle as the landmark. The radial artery was identified on the radial side of the wound and retracted laterally. The FCR being a landmark to reach the scaphoid was searched for and was found to be absent. It was found to be replaced by a thin and rudimentary fibrous band lying radial to a very broad palmaris longus (PL) tendon [Figure 1]. Proximal exploration was not done. The volar aspect of the radial side of the wrist joint is usually exposed by retracting the FCR medially after incising the tendon sheath to free the tendon from its tunnel. In our case, with absent FCR, no such landmark was available and the wrist capsule was directly approached and incised open to expose the distal two-thirds of the scaphoid. The procedure was completed with excision of the sclerotic segment of the scaphoid, iliac bone grafting of the defect and fixation with a headless compression screw.

Anatomical variations in the FCR muscle have been described by Bergman ${ }^{[7]}$ with respect to its origin, insertion and having an additional slip from other muscles. Rumball and Tonkin ${ }^{[5]}$ reported a case of an absent FCR in a patient undergoing tendon transfer for a posterior

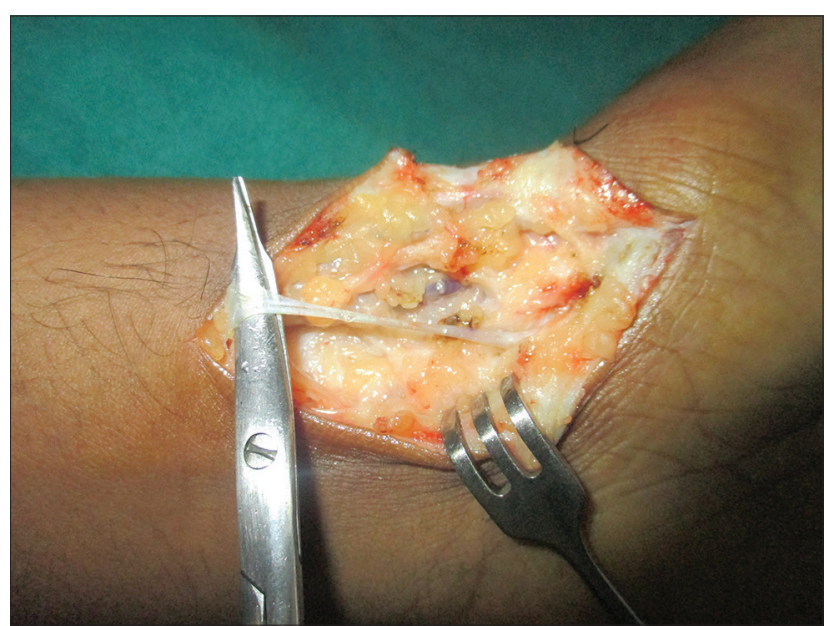

Figure 1: Thin and rudimentary fibrous band replacing flexor carpi radialis

interosseous nerve palsy. The proposed transfers were FCR to extensor digitorum communis (EDC) and flexor digitorum superficialis (FDS) of the ring finger to extensor pollicis longus (EPL). At the time of surgery, both the FCR and PL were absent. The procedure had to be changed and the transfers carried out were FDS of the ring finger to EDC, routed around the ulnar border of the forearm and FDS of the middle finger to rerouted EPL. Sofos and Riaz $^{[6]}$ reported a case of absent FCR encountered intra-operatively in a patient with first carpometacarpal arthritis, in whom a trapeziectomy with FCR ligament reconstruction was planned. With absent FCR, they converted the procedure into a simple trapeziectomy. The absence of the FCR, found intra-operatively as mentioned above, can jeopardise surgeries. Especially for tendon transfers, it is imperative to establish beyond doubt the presence of FCR by pre-operative clinical examination. In its absence, other tendons such as PL may be confused for the FCR by superficial examination. In case of any doubt, an ultrasonography of the wrist can be used to identify the tendon.

The operating surgeon, intending to use the FCR for tendon transfer or as a tendon graft, should be highly aware of the possibility of such a variation, where it may pose difficulties and even a change in the planned surgical procedure. Hence, it is imperative that one checks the presence of FCR in any case requiring it as a surgical landmark, donor for tendon transfer or tendon graft.

\section{Financial support and sponsorship}

Nil. 


\section{Conflicts of interest}

There are no conflicts of interest.

\section{Vigneswaran Varadharajan, Praveen Bhardwaj, S. Raja Sabapathy}

Department of Plastic, Hand and Reconstructive Microsurgery, Ganga Medical Centre and Hospitals Pvt. Ltd.,

Coimbatore, Tamil Nadu, India

Address for correspondence: Dr. Vigneswaran Varadharajan, Department of Plastic, Hand and Reconstructive Microsurgery, Ganga Medical Centre and Hospitals Pvt. Ltd., 313, Mettupalayam Road, Coimbatore - 641 043,

Tamil Nadu, India. E-mail: vigneshdr87@gmail.com

\section{REFERENCES}

1. Boyes J. Tendon transfers for radial palsy. Bull Hosp Jt Dis 1960;21:97-105.

2. Brand P. Tendon transfers in the forearm. In: Flynn JE, editor. Hand Surgery. Baltimore: Williams and Wilkins; 1975. p. 189-200.

3. Burton RI, Pellegrini VD Jr. Surgical management of basal joint arthritis of the thumb. Part II. Ligament reconstruction with tendon interposition arthroplasty. J Hand Surg Am 1986;11:324-32.

4. Eaton RG, Littler JW. Ligament reconstruction for the painful thumb carpometacarpal joint. J Bone Joint Surg Am 1973;55:1655-66.

5. Rumball KM, Tonkin MA. Absence of flexor carpi radialis. J Hand Surg Br 1996;21:778.

6. Sofos SS, Riaz M. Absence of flexor carpi radialis during an elective carpometacarpal arthroplasty of the thumb: A rare anatomical variation. Case Rep Med 2016;2016:7853487.

7. Bergman RA. Compendium of Human Anatomic Variation: Text, Atlas and World Literature. Baltimore: Urban and Schwarzenberg; 1988.

This is an open access article distributed under the terms of the Creative Commons Attribution-NonCommercial-ShareAlike 3.0 License, which allows others to remix, tweak, and build upon the work non-commercially, as long as the author is credited and the new creations are licensed under the identical terms.

\begin{tabular}{|l|l|}
\hline \multicolumn{2}{|c|}{ Access this article online } \\
\hline Quick Response Code: & Website: \\
\hline & www.ijps.org \\
\cline { 2 - 2 } & DoI: \\
\hline
\end{tabular}

How to cite this article: Varadharajan V, Bhardwaj P, Sabapathy SR. Absence of flexor carpi radialis: A rare anatomical variation with clinical significance. Indian J Plast Surg 2017;50:111-2.

(C) 2017 Indian Journal of Plastic Surgery | Published by Wolters Kluwer - Medknow 